\title{
OBLIGACIONES ESTATALES RESPECTO DE LA INCLUSIÓN DE LAS PERSONAS CON DISCAPACIDAD EN EL MERCADO LABORAL*
}

STATE DUTIES REGARDING THE INCLUSION IN THE LABOR MARKET OF PERSONS WITH DISABILITIES

OBLIGATIONS D'ETAT SUR L'INCLUSION DES PERSONNES HANDICAPÉES AU MARCHÉ DU TRAVAIL

Juan Pablo ALEMÁN IZAGUIRRE ${ }^{* *}$

\section{INTRODUCCIÓN}

$\square$ 1 presente texto tiene por objeto comentar la Comunicación núm. 2/2010 (en adelante, la Comunicación) del Comité sobre los Derechos de las Personas con Discapacidad ${ }^{1}$ (en lo subsecuente, el Comité) en la que se analizó si Alemania había cumplido su obligación de fomentar el derecho al trabajo frente a los argumentos formulados por Thomas Gröniger y su representación en cuanto a que no se le habría facilitado su inclusión en el mercado laboral.

Inicialmente conviene señalar que el Comité referido es un órgano creado por el Protocolo Facultativo de la Convención sobre los Derechos de las Personas con Discapacidad con el objeto de recibir y considerar comunicaciones presentadas por personas o grupos de personas, sujetos a su jurisdicción, que aleguen ser víctimas de una violación por un Estado parte en relación a

\footnotetext{
* Recibido el 4 de agosto de 2017 y aprobado para su publicación el 4 de septiembre de 2017.

** Maestro en derecho internacional de los derechos humanos por la Universidad de Notre Dame. Actualmente colabora en la ponencia del ministro José Ramón Cossío Díaz en la Suprema Corte de Justicia de la Nación.

1 Comité de los Derechos de las Personas con Discapacidad, Comunicación núm. 2/2010, CRPD/C/D/2/2010, 7 de julio de 2014.
}

\section{Revista Latinoamericana de Derecbo Social} Núm. 26, enero-junio de 2018, pp. 155-216 
cualquiera de las disposiciones de la Convención sobre los Derechos de las Personas con Discapacidad (en adelante, la Convención).

Asimismo, resulta pertinente realizar algunos apuntes sobre la Convención. Este tratado internacional es el primer instrumento en materia de derechos humanos creado en el presente siglo, entró en vigor ${ }^{2}$ el 3 de mayo de 2008 y, actualmente, 174 Estados son parte del mismo.

La relevancia de esta Convención se relaciona con el ejercicio de los derechos de las personas con discapacidad, ya que introduce un cambio de paradigma respecto del entendimiento de las discapacidades al transitar del modelo médico al denominado modelo social.

En efecto, desde el preámbulo de este instrumento internacional y de la redacción de su artículo 1o. queda en evidencia que la discapacidad es un concepto que ha evolucionado y, por tanto, ya no es entendido únicamente desde un punto de vista clínico como una deficiencia física, mental, intelectual o sensorial de una persona a largo plazo, sino que es una condición que resulta de la interacción de cualquiera de esas deficiencias con diversas barreras sociales que impiden la plena y efectiva participación de las personas en la sociedad, en igualdad de condiciones respecto de las demás.

Es precisamente esa lógica la que impregna el contenido del artículo 27 de la Convención, cuyo cumplimiento se analizó en la Comunicación que ahora se comenta, el cual reconoce el derecho de las personas con discapacidad a trabajar en igualdad de condiciones con las demás.

En ese sentido, los Estados parte asumieron diversas obligaciones para salvaguardar este derecho y, en consecuencia, derribar las barreras que enfrentan las personas con discapacidad para poder acceder al mercado laboral. Entre ellas destacan, para efectos del presente comentario, la obligación de permitir que las personas con discapacidad tengan acceso a programas generales de orientación técnica y vocacional, servicios de colocación y formación profesional (artículo 27. 1. d); la de alentar las oportunidades de empleo y promoción profesional de las personas con discapacidad y apoyarlas para la búsqueda, obtención, mantenimiento y retorno al empleo (artículo 27. 1. e); $y$, finalmente, la de promover el empleo de personas con discapacidad en el

2 De conformidad con el artículo 45.1, la Convención entraría en vigor el trigésimo día a partir de la fecha en que haya sido depositado el vigésimo instrumento de ratificación o adhesión al tratado. 
sector privado mediante políticas y medidas pertinentes, que pueden incluir programas de acción afirmativa (artículo 27. 1. h).

De lo descrito resulta evidente que los Estados tienen, a la luz del citado artículo, obligaciones que implican el deber de crear los programas, medios y servicios referidos para garantizar la inclusión de las personas con discapacidad en el mercado laboral.

Una vez dicho lo anterior conviene iniciar con el análisis de la Comunicación objeto del presente comentario.

\section{OBLIGACIONES ESTATALES RESPECTO DE LA INCLUSIÓN}

DE LAS PERSONAS CON DISCAPACIDAD EN EL MERCADO LABORAL

En la especie, el procedimiento se inició ante el Comité a raíz de la comunicación realizada el 25 de julio de 2010 por Liliane Gröniger en la que ella, su hijo Thomas y su marido Erhard, también de apellidos Gröniger, fueron señalados como víctimas, y se sostuvo que Alemania había violado los derechos que le asistían a su hijo — una persona con discapacidad - en virtud de los artículos 3o., 4o., 8o. y 27 de la Convención. La Comunicación de referencia fue declarada admisible por el Comité el 18 de septiembre de 2012, ocasión en la que también solicitó información adicional sobre los hechos del caso a las entonces presuntas víctimas.

Del análisis integral de la Comunicación objeto del presente comentario se puede apreciar que las víctimas alegaron lo siguiente:

- La autora de la petición se reunió en noviembre de 2009 con el jefe del Servicio de Integración Especial y un representante de la Oficina de Integración de Colonia, ante quienes planteó la situación de discriminación que enfrentan las personas con discapacidad en cuanto a su integración; ocasión en la que se le dijo que la autoridad regional no disponía de ningún medio legal para ayudar a su hijo.

- Thomas Gröniger estuvo inscrito en las agencias de empleo desde el 2002. A pesar de ello, no tuvo acceso a los programas de formación y orientación profesional de carácter general técnico y continuo ni tampoco a los servicios de colocación.

- Se argumentó que Thomas Gröniger había visitado a un logópeda y a un fisioterapeuta, asimismo se ejercitaba en un club local de tenis de 
mesa para mantener su capacidad física y mental, y que era su familia la que financiaba esas actividades.

- Durante octubre y noviembre de 2009 completó un curso de formación como cajero, pero la agencia estatal de empleo se negó a proporcionarle apoyo financiero para tal efecto al aducir que el curso no era eficaz en función de su costo, situación que fue denunciada ante el Tribunal de lo Social de Colonia, instancia que, después de tres años, no había pronunciado una resolución.

- En los periodos comprendidos entre marzo y abril de 2010 y 2011 tomó un curso de contabilidad y teneduría de libros que, de igual manera, fueron costeado por su familia, pues la agencia de empleo no proporcionó ni la formación ni el apoyo financiero necesarios.

- Thomas Gröniger no recibió apoyo ni asistencia de la agencia de empleo mientras buscaba trabajo e incluso, después de haber solicitado empleo en al menos diez posiciones laborales para las que también fue entrevistado, los posibles empleadores rechazaron sus solicitudes tras ponerse en contacto con la agencia de empleo.

- Los esfuerzos de la agencia de empleo se limitaron a enviarle ofertas que no eran más que anuncios de empresas de carácter general y a menudo estaban atrasadas o no se adecuaban a sus necesidades. En específico, se presentó información sobre una oferta de trabajo vacante que fue hecha del conocimiento de la víctima con más de tres meses de retraso.

- De conformidad con el artículo 219 del Código Social, Thomas Gröniger sólo era susceptible de recibir un subsidio de integración para el empleo si podía recuperar plenamente su capacidad de trabajo en un plazo de tres años, lo cual las víctimas estimaron que impedía la integración en el mercado laboral.

- Se dijo también que el subsidio de integración era la única medida de acción afirmativa que existía para ayudar a las personas con discapacidad a incorporarse al mercado de trabajo, sin embargo, el acceso al subsidio se veía obstaculizado por la legislación social.

De esta manera, con posterioridad a un intercambio de información respecto de los argumentos reseñados entre las víctimas y el Estado, y al análisis sobre la admisibilidad de la Comunicación, el Comité procedió a examinar el fondo del asunto. 
Inicialmente se pronunció respecto de la compatibilidad de las políticas en torno al subsidio de integración con las disposiciones de la Convención. Para lo anterior, tomó en consideración los alegatos de las víctimas en cuanto a que el subsidio referido sólo puede ser recibido por personas con discapacidad que puedan recuperar plenamente, en un plazo de 36 meses, sus facultades para desempeñarse laboralmente, y que el derecho a solicitar ese subsidio corresponde exclusivamente al empleador.

$\mathrm{Al}$ respecto, el Estado argumentó que la víctima reunía los requisitos para recibir el subsidio de integración siempre que se cumplieran las condiciones legales para su asignación, consistentes en que el empleador hiciera una oferta vinculante de trabajo y solicitara el subsidio, tras lo cual la agencia de empleo evaluaría la situación y adoptaría una decisión acerca de la duración y cuantía del subsidio. Sin embargo, según lo afirmado por el Estado, el subsidio sólo podía llegar a ser — como máximo— del 70\% del salario del trabajador y no sería prorrogable por más de 60 meses.

De esta manera, el Comité observó que la intención del programa de subsidios de integración parecía ser la de alentar a los empleadores privados a contratar personas con discapacidad. Sin embargo, notó también que en la práctica se exige a los potenciales patrones pasar por un proceso adicional de solicitud, cuya duración y resultado no se reconocen con certeza y que la persona con discapacidad no tiene ninguna participación en el proceso.

Así, afirmó que esta política pública respondía al modelo médico de la discapacidad en razón de que tiende a considerar la misma como algo transitorio que, en consecuencia, puede superarse o curarse con el transcurso del tiempo. Por lo tanto, concluyó que la política era contraria a los principios generales establecidos en el artículo 3o. de la Convención, ${ }^{3}$ leídos conjuntamente con los párrafos i y j del preámbulo. ${ }^{4}$

3 Artículo 3o. "Principios Generales. Los principios generales de la presente convención serán: a) El respeto de la dignidad inherente, la autonomía individual, incluida la libertad de tomar las propias decisiones, y la independencia de las personas; b) La no discriminación; c) La participación e inclusión plenas y efectivas en la sociedad; d) El respeto por la diferencia y la aceptación de las personas con discapacidad como parte de la diversidad y la condición humanas; e) La igualdad de oportunidades; $f$ La accesibilidad; g) La igualdad entre el hombre y la mujer; h) El respeto a la evolución de las facultades de los niños y las niñas con discapacidad y su derecho a preservar su identidad".

4 Preámbulo “...i) Reconociendo además la diversidad de las personas con discapacidad, 
Posteriormente, el Comité enfatizó que el artículo 27 de la Convención conlleva la obligación de los Estados partes de crear un entorno favorable y propicio al empleo, incluso en el sector privado; que en el artículo 4o., párrafo 1, inciso a, de la Convención se impone a los Estados la obligación general de adoptar todas las medidas legislativas, administrativas y de otra índole que sean pertinentes para hacer efectivos los derechos de la Convención en relación con el trabajo y el empleo; y, a su vez, que en el artículo 3o. se establece que la legislación, políticas y prácticas, los Estados deben guiarse por el respeto de la dignidad inherente, la autonomía individual, la independencia de las personas, la no discriminación, la participación e inclusión plenas y efectivas en la sociedad y la igualdad de oportunidades.

A la luz de lo anterior, el Comité opinó que el modelo existente para la concesión de subsidios de integración no fomentaba de manera efectiva el empleo de las personas con discapacidad. Lo anterior en razón de las dificultades con que se enfrentan los potenciales patrones al tratar de acceder al subsidio de integración al que tienen derecho por emplear a una persona con discapacidad, mismas que afectan la eficacia del sistema y generan como consecuencia el situar a los solicitantes en una posición de desventaja y de discriminación indirecta. De esta manera se concluyó que el sistema de subsidios de integración resulta incompatible con las obligaciones estatales emanadas de los artículos 27, párrafo 1 inciso $b$ en conjunto con los artículos 3o., párrafos $a, b, c$ y $e$, el artículo 4o., párrafo 1, incisos $a,{ }^{5}$ y el artículo 5o., párrafo $1,{ }^{6}$ de la Convención.

Ahora bien, frente a la afirmación de las víctimas en cuanto a que el subsidio de integración era la única medida de acción afirmativa disponible para ayudar a las personas con discapacidad a incorporarse al mercado laboral y lo

\footnotetext{
j) Reconociendo la necesidad de promover y proteger los derechos humanos de todas las personas con discapacidad, incluidas aquellas que necesitan un apoyo más intenso...".

5 Artículo 4o. "Obligaciones generales. 1. Los Estados Partes se comprometen a asegurar y promover el pleno ejercicio de todos los derechos humanos y las libertades fundamentales de las personas con discapacidad sin discriminación alguna por motivos de discapacidad. A tal fin los Estados Partes se comprometen a: a) Adoptar todas las medidas legislativas, administrativas y de otra índole que sean pertinentes para hacer efectivos los derechos reconocidos en la presente Convención...”.

6 Artículo 5o. "Igualdad y no discriminación. 1. Los Estados Partes reconocen que todas las personas son iguales ante la ley en virtud de ella y que tienen derecho a igual protección legal y a beneficiarse de la ley en igual medida sin discriminación alguna...".
} 
argumentado por el Estado respecto de una amplia variedad de otras medidas de las que Thomas Gröniger pudiera haber sido beneficiario, el Comité observó que el Estado no logró especificar cuáles de esas medidas resultaban aplicables al caso específico y, además, que las medidas aplicadas por las autoridades alemanas para facilitar su integración en el mercado de trabajo se redujeron a la concesión de prestaciones por desempleo durante periodos de tiempo no especificados, la celebración de reuniones de asesoramiento, proporcionarle anuncios de vacantes de empleo —algunas de ellas expiradas- y su inclusión en una "medida general de colocación".

Adicionalmente sostuvo el Comité que el Estado parecía ser de la opinión de que los esfuerzos de Thomas Gröniger para mejorar sus cualificaciones mediante la continuidad de su educación y el hecho de que hubiera aceptado empleos parciales constituían un obstáculo para las actividades de las agencias de empleo.

De esta manera, al notar que la gama de medidas aplicadas en la especie fue limitada en comparación con la lista de medidas disponibles con las cuales contaba el Estado, el Comité se pronunció en el sentido de entender que en el artículo 27, párrafos 1 , incisos $d$ y e se consagra el derecho de las personas con discapacidad a disfrutar de medidas apropiadas de fomento de las posibilidades de empleo, como el acceso efectivo a los servicios generales de colocación, así como a recibir asistencia en la búsqueda y obtención de empleo, lo cual lo llevó a concluir que, en el caso específico, Alemania no había adoptado las medidas pertinentes para la integración de Thomas Gröniger al mercado laboral con lo cual había vulnerado el contenido de los artículos 27, párrafos 1, inciso $d$, y párrafo 2 en conjunto con los artículos 3o., párrafos $a, b, c$ y $e$; 4o., párrafos 1 , inciso $a$ y $b$; y 5o., párrafo 1 de la Convención.

Teniendo en cuenta lo antes reseñado, el Comité formuló al Estado dos recomendaciones consistentes en: a) remediar el incumplimiento de sus obligaciones convencionales en relación con Thomas Gröniger, aplicando todas las medidas disponibles para fomentar de manera eficaz sus posibilidades de empleo y, además, pagar una indemnización apropiada, incluida una compensación por los gastos de tramitación del caso; y, b) modificar su legislación, en especial respecto del sistema de subsidios de integración, para evitar que hechos similares al de la especie se repitan en el futuro. 
Desde la óptica del autor, la Comunicación que se comenta debe constituir un llamado de atención para los Estados signatarios de la Convención en razón de que conforma un nuevo entendimiento de sus obligaciones en relación al derecho al trabajo.

En efecto, desde una concepción tradicional de las obligaciones en esta materia, el Comité de Derechos Económicos Sociales y Culturales (en adelante, Comité DESC) de las Naciones Unidas ha señalado que el derecho al trabajo "no debe entenderse como un derecho absoluto e incondicional a obtener empleo". 7 En ese sentido también ha sostenido que entre las obligaciones que incumben a los Estados partes en relación con el derecho de referencia se encuentran el derecho de todas las personas a decidir libremente aceptar o elegir trabajo; no ser obligadas de alguna manera a ejercer o efectuar un trabajo: el derecho de acceso a un sistema de protección que garantice a cada trabajador su acceso a empleo y el derecho a no ser privado injustamente del mismo. ${ }^{8}$

Por otra parte, el mismo Comité DESC ha concluido que el trabajo al que se refiere el Pacto Internacional de Derechos Económicos Sociales y Culturales (en lo sucesivo, PIDESC) en su artículo 6o., ${ }^{9}$ debe entenderse como un trabajo digno en cuanto a que debe respetar los derechos de la persona humana y los derechos relativos a condiciones de seguridad laboral y remuneración.

Ahora bien, en su misma observación general número 18, el Comité DESC sostuvo que el ejercicio laboral, en todas sus formas, supone la existencia de tres elementos cuya aplicación dependerá de las condiciones existentes en cada Estado, a saber: disponibilidad — que los Estados cuenten con servicios especializados que ayuden y apoyen a las personas para permitirles identificar

7 Comité de Derechos Económicos Sociales y Culturales, Observación general núm. 18. El derecho al trabajo, E/C.12/GC/18, 24 de noviembre de 2005, párr. 6.

8 Idem.

9 Artículo 6o. "1. Los Estados Partes en el presente Pacto reconocen el derecho a trabajar, que comprende el derecho de toda persona a tener la oportunidad de ganarse la vida mediante un trabajo libremente escogido o aceptado, y tomarán medidas adecuadas para garantizar este derecho. 2. Entre las medidas que habrá de adoptar cada uno de los Estados Partes en el presente Pacto para lograr la plena efectividad de este derecho deberá figurar la orientación y formación técnico-profesional, la preparación de programas, normas y técnicas encaminadas a conseguir un desarrollo económico, social y cultural constante y la ocupación plena y productiva, en condiciones que garanticen las libertades políticas y económicas fundamentales de la persona humana". 
empleos disponibles y acceder a ellos—; accesibilidad — que se pueda acceder al trabajo sin discriminación, que sea accesible físicamente y que se cuente con medios para obtener acceso al empleo mediante redes de información-; y, finalmente, aceptabilidad y calidad — que el trabajador tenga condiciones justas y favorables de trabajo-.${ }^{10}$

De lo anterior se desprende, con meridiana claridad, que las obligaciones respecto al derecho al trabajo contenidas en el PIDESC y desarrolladas por el Comité DESC son de mucho menor intensidad que las contempladas en la Convención sobre los Derechos de las Personas con Discapacidad y las que delineó el Comité de ese tratado en la Comunicación objeto del presente comentario.

En primer término debe resaltarse que, de conformidad con el criterio del Comité DESC, las obligaciones en materia del trabajo no implican un derecho absoluto e incondicional a obtener un trabajo y que, en todo caso, las demás obligaciones que aquí han sido descritas dependen siempre de las condiciones económicas existentes en cada Estado. Lo anterior abre siempre la puerta a los Estados al tentador argumento sobre la necesidad de utilizar los recursos disponibles en necesidades más apremiantes para las personas, condición que impacta negativamente en el goce efectivo del derecho al trabajo y en el cumplimiento de las obligaciones estatales en la materia.

Adicionalmente puede entenderse que los deberes estatales en materia del trabajo a la luz del PIDESC implican más bien obligaciones importantes sobre la libertad de elegir el trabajo y en relación con las condiciones dignas del mismo, relegando a un segundo plano una posible intervención del Estado para lograr que las personas puedan identificar algún empleo disponible y, eventualmente, acceder a él.

De esta manera resultan claras las diferencias entre las obligaciones que le asisten a los Estados para lograr la inclusión de la generalidad de personas al mercado laboral frente a las que asumieron en esta materia al firmar la Convención sobre los Derechos de las Personas con Discapacidad y, muy especialmente, a la manera en la que el Comité las ha entendido en la Comunicación que aquí ha sido reseñada.

10 Comité de Derechos Económicos Sociales y Culturales, Observación General núm. 18, El derecho al trabajo, cit., párr. 12. 


\section{CONCLUSIONES}

En principio, conviene resaltar que del criterio sostenido por el Comité no se advierte alusión alguna a la situación económica del país al que se refiere ni a la disponibilidad de recursos para el cumplimiento de sus obligaciones en la materia.

Por otra parte, la diferencia más relevante radica en el rol que los Estados tienen que asumir en el cumplimiento de su obligación de promover la inclusión de las personas con discapacidad en el mercado laboral, pues el mismo debe ser significativamente más activo en esta materia, al implicar la implementación de acciones de orientación y capacitación, servicios de colocación, de promoción, incluso en el sector privado, y de igual manera, la implementación de programas de acciones afirmativas.

Esta intensidad en las obligaciones estatales referidas obedece, sin duda, al modelo social de las discapacidades que impone a los Estados partes a la Convención un deber de derribar las barreras que impiden que las personas con discapacidad puedan acceder, en condiciones de igualdad, al mercado laboral a través de un esfuerzo mucho más intenso. De ahí la pertinencia del presente comentario.

\section{Fuentes CONSUltadas}

Comité de Derechos Económicos Sociales y Culturales, Observación general núm. 18, El derecho al trabajo, E/C.12/GC/18, 24 de noviembre de 2005.

Comité de los Derechos de las Personas con Discapacidad, Comunicación núm. 2/2010, CRPD/C/D/2/2010, 7 de julio de 2014.

Convención sobre los Derechos de las Personas con Discapacidad, Nueva York aprobada el 13 de diciembre de 2006. TS 